\title{
Complete sequence of mitochondrial DNA control region of the Japanese serow Capricornis crispus (Bovidae: Caprinae)
}

\author{
Hideo Okumura \\ Wildlife Ecology Laboratory, Department of Wildlife Biology, Forestry and Forest Products Research Institute, Tsukuba, \\ Ibaraki 305-8687, Japan
}

\begin{abstract}
The Japanese serow, Capricornis crispus, is an indigenous species to Japan. It has been strictly protected for nearly half a century, whereas culling for control has been permitted in some areas since the late 1970s. In order to investigate the intraspecific genetic diversity of the Japanese serow, a study on the mtDNA control region was conducted. In the present study, the complete nucleotide sequences of the control region (1031 bp) and its flanking proline tRNA gene (65 bp) from six serows were determined. In total, ten variable sites were observed in control region sequences, resulting in four different haplotypes. All of the substitutions among these haplotypes were transitions. Central, left and right domains of the control region were identified by comparison with cow sequences. Conserved sequence block-1 (CSB-1) and a polypyrimidine tract were also identified in the right domain. Two tandemly repeated sequences of $76 \mathrm{bp}$ were found in the left domain. These features were compared with four Caprinae species. Sequences of the central domain, CSB-1 and polypyrimidine tract were homologous among them. The copy number of tandem repeat units varied among species. The estimated genetic distances suggest that the Formosan serow is probably a distinct species from the Japanese serow.
\end{abstract}

Key words: Capricornis crispus, control region, Japanese serow, mitochondrial DNA, tandem repeat.

The Japanese serow, Capricornis crispus (Temminck, $1845)$, is an indigenous species to Japan. It is a monogamous bovid and a typical solitary forest-dweller inhabiting mountainous areas in the three main islands of Japan, namely, Honshu, Shikoku, and Kyushu Is.

The genus Capricornis is considered as one of the most primitive in subfamily Caprinae, belonging to tribe Rupicaprini (Simpson 1945). Within the tribe Rupicaprini, serows and gorals have been assigned to separate genera (Dolan 1963; Mead 1989; Nowak 1999), Capricornis and Naemorhedus, although they are closely related. Groves and Grubb (1985) suggested that these two groups, serows and gorals, should be assigned to one genus, Naemorhedus. Some authors have followed this opinion (Corbet and Hill 1992; Grubb 1993).

The genus Capricornis includes three species, $C$. sumatraensis (serow), C. crispus (Japanese serow), and C. swinhoei (Formosan serow) (Simpson 1945; Nowak 1999). The distribution of the serow is from northwest- ern India to southeastern China, Indochinese Peninsula and the island of Sumatra. The Formosan serow, which occurs only in the island of Taiwan, is sometimes treated as a subspecies of the Japanese serow (Dolan 1963; Corbet 1978), but is also considered a distinct species (Groves and Grubb 1985; Corbet and Hill 1992). In either case, the Formosan serow has usually been regarded as more closely related to the Japanese serow than to the serow. Recently molecular phylogenetic studies using mtDNA cytochrome $b$ gene region showed that the Formosan serow is probably a sister species of the serow, and is neither a subspecies of the Japanese serow nor a sister species (Chikuni et al. 1995; Min et al. 2004). New evidence is necessary to clarify the intrageneric relationships among the three Capricornis species.

The Japanese serow was designated as a "Natural Monument of Japan" by the Japanese Government in 1934, and in 1955 its status was raised to a "Special

E-mail: okumurah@ffpri.affrc.go.jp 
Natural Monument" because of continuous poaching. Subsequently, due to strict protection, the Japanese serow has rapidly recovered its numbers in most of Honshu. As a result of the recovery, damage to planted trees and crops caused by this species became a social problem in the 1970s. This was the first case of severe conflict with wildlife conservation in Japan. The Japanese Government has taken some conservation measures since the end of the 1970s. On the other hand, culling for control has been permitted in some areas under special license from the Government (Maruyama et al. 1997). At the present time, the Japanese serow population is not threatened on the island of Honshu, whereas on the other two islands of Shikoku and Kyushu most of the local populations are still small and isolated.

A large number of studies have been published on the biology of the Japanese serow, but the current status of each local population has not been sufficiently investigated for management.

A molecular genetic approach may provide reliable information on the genetic diversity between and within species. In particular, mitochondrial DNA (mtDNA) is a useful genetic marker for studying recently diverged species and intraspecific populations because it is maternally inherited (Giles et al. 1980; Wilson et al. 1985) with no recombination and its mutation rate is about ten times faster than that of single-copy nuclear DNA (Brown et al. 1979). Especially, the control region (or the D-loop region) is the most variable region in the mammalian mtDNA genome. This non-coding region is characterized by rapid change in sequence and length (Saccone et al. 1991). Hence, the mitochondrial control region is an ideal marker for characterizing the structure of intraspecific genetic variation within and among local populations. Recently the number of studies on the genetic information of mammalian populations using the control region has been increasing (e.g. Arctander et al. 1996; Matsuhashi et al. 1999; Matthee and Robinson 1999; Nagata et al. 1999; Birungi and Arctander 2000; Yoshida et al. 2001; Watanobe et al. 2003; Marmi et al. 2004).

Control region sequences will provide useful information on the genetic diversity of the Japanese serow populations. But there has been little work on the genetic information of the Japanese serow populations, and no information on the mtDNA control region, although Min et al. (2004) presented preliminary data on intraspecific variation of the mtDNA cytochrome $b$ gene sequences. Because the cytochrome $b$ gene encodes a protein, its sequence is generally more constrained than the non- coding control region. It thus shows less variation than the control region. When intraspecific genetic variation is investigated, the cytochrome $b$ gene is used as a molecular marker suitable for identifying variation at a broader scale than the control region. Min et al. (2004) recognized five different haplotypes of partial cytochrome $b$ gene sequence among 16 Japanese serows, which were collected from northeastern and central Honshu Is., and from Kyushu Is.

In order to investigate the genetic diversity of local populations of the Japanese serow, a study on the mtDNA control region was conducted. In the present study, the complete control region and its flanking proline tRNA gene sequences are determined, and some features of the control region, i.e. well-conserved and variable domains, conserved sequence blocks (CSBs) and tandem repeats, are discussed in comparison with Caprinae species. The genetic distances between the Japanese serow and the Formosan serow are estimated.

\section{Materials and methods}

\section{Sample collection and extracting DNA}

Liver tissue samples from six Japanese serows were collected at Kiso-fukushima Town in Nagano Pref., central Honshu in 1997 (Table 1, Fig. 1). Because the Japanese serow is designated as a "Special Natural Monument" species by the Japanese Government, the hunting of serows is prohibited. All of these samples were taken from animals culled by the local government under special license from the Japanese national government. Serows were shot at the appointed capture areas of 50-100 hectares which were mainly covered by plantation forests of Hinoki cypress Chamaecyparis obtusa. After collection, fresh tissue was preserved in $99.5 \%$ ethanol and subsequently stored at $-20^{\circ} \mathrm{C}$ or $-80^{\circ} \mathrm{C}$. Total DNA (i.e. genomic and mitochondrial) was extracted from tissues using QIAamp DNA Mini Kit (QIAGEN, Cat. No. 51304).

\section{Direct sequencing of the mtDNA control region using $P C R$}

To amplify and/or sequence the mtDNA control region of the Japanese serow, seven newly designed primers were used (Table 2, Fig. 2).

Two primers, LS-1 and HS-3, were designed by referring to the published primers and flanking tRNA gene sequences of artiodactyls (Anderson et al. 1982; Kocher et al. 1989; Zardoya et al. 1995; Takada et al. 1997; 
Table 1. Samples of Japanese serow analyzed in this study and identified haplotypes.

\begin{tabular}{cccc}
\hline Sample Name & Date & Gender & Haplotypes \\
\hline KF-H8-317 & 1997.1 .18 & $\mathrm{f}$ & Kiso-a \\
KF-H8-318 & 1997.1 .19 & $\mathrm{~m}$ & Kiso-b \\
KF-H8-319 & 1997.1 .19 & $\mathrm{~m}$ & Kiso-d \\
KF-H8-320 & 1997.1 .19 & $\mathrm{f}$ & Kiso-c \\
KF-H8-321 & 1997.1 .19 & $\mathrm{f}$ & Kiso-b \\
KF-H8-322 & 1997.1 .19 & $\mathrm{~m}$ & Kiso-b \\
\hline
\end{tabular}

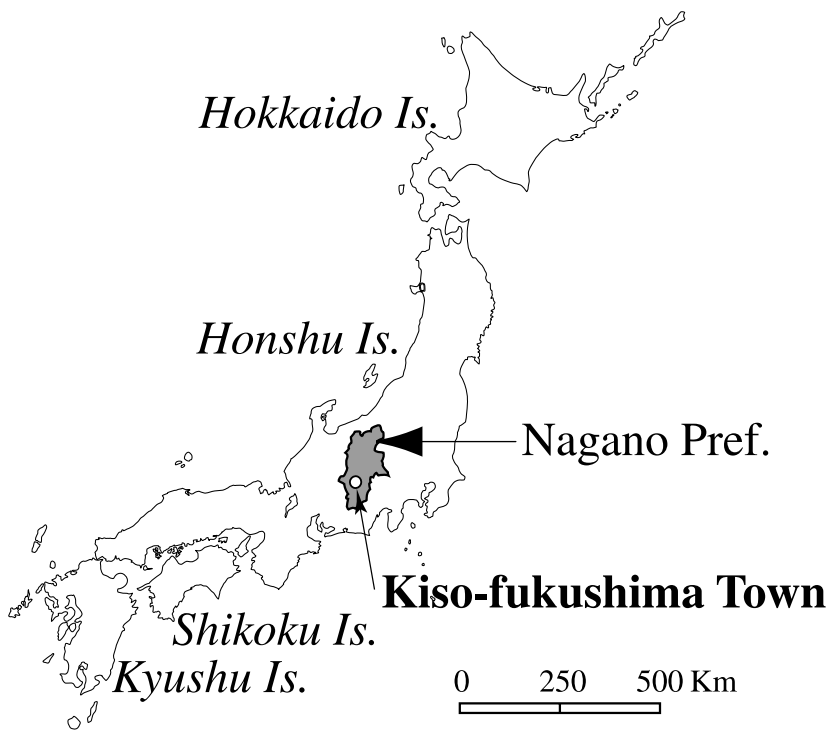

Fig. 1. Map of sample collecting locality.

Nagata et al. 1998) and human (Anderson et al. 1981). LS- 1 and HS-3 are located in the upstream threonine tRNA gene region and in the downstream phenylalanine tRNA gene region respectively (Fig. 2). With the primer pair LS-1/HS-3, symmetric PCR (Kocher et al. 1989) was performed using a PCR reagent kit (Takara Shuzo Co. Ltd.) in order to amplify double-stranded DNA of the target region. One microliter of the DNA extract was subjected to PCR amplification in a total volume of $50 \mu 1$ of a reaction mixture including $10 \mathrm{mM}$ Tris- $\mathrm{HCl}$ buffer (pH 8.3), $50 \mathrm{mM} \mathrm{KCl}, 1.5 \mathrm{mM} \mathrm{MgCl}_{2}$, each dNTP at 0.2 $\mathrm{mM}, 1.25 \mathrm{U}$ of Taq DNA polymerase, and each primer at $0.25 \mu \mathrm{M}$. The thermocycler programs for PCR amplification were as follows: denaturation for $5 \mathrm{~min}$ at $97^{\circ} \mathrm{C}$ was performed before the cycle reaction, and each cycle consisted of $1 \mathrm{~min}$ at $94^{\circ} \mathrm{C}$ for denaturation, $30 \mathrm{sec}$ at $56^{\circ} \mathrm{C}$ for annealing, and $30 \mathrm{sec}$ at $72^{\circ} \mathrm{C}$ for extension. After 25 cycles, the reaction was completed without further incubation.

Using the double-stranded PCR product as a template,
Table 2. Primers for amplification and sequencing of the Japanese serow mtDNA control region.

\begin{tabular}{cl}
\hline Primer name & \multicolumn{1}{c}{ Sequence (5' to 3') } \\
\hline LS-1 & AATATACTGGTCTTGTAAACC \\
HS-3 & AGGCATTTTCAGTGCCTTGC \\
\hline LS-3 & TCTTTCTTCAGGGCCATCTC \\
LS-6 & CATTAAATGATTTACCCCATGC \\
LS-7 & GTACATACCCTTAATTTGCCTGGG \\
\hline HS-5 & CCATCGAGATGTCTTATTTAAGAGG \\
HS-7 & CATGTACATGCTTATACGCATGGGG \\
\hline
\end{tabular}

dideoxy terminator cycle sequencing was performed at first with the primer LS-1 and with HS-3 respectively. The BigDye Terminator Cycle Sequencing FS Ready Reaction Kit (Applied Biosystems, Part No. 4303152) was used according to the manufacturer's instructions. The sequences of DNA labeled with dye-terminators were read using the ABI PRISM 310 Genetic Analyzer (Applied Biosystems).

From partial sequences obtained and the published sequences of artiodactyls (Anderson et al. 1982; Zardoya et al. 1995; Takada et al. 1997), several specific primers for the mtDNA control region sequences of the Japanese serow were newly designed and tested for sequencing. Finally, five primers, LS-3, LS-6, LS-7, HS-5, and HS-7, were used for sequencing (Table 2, Fig. 2).

\section{Comparison with additional mammalian sequences}

Sequence comparisons among control regions in several mammalian species allowed the identification of a well-conserved central domain with two more variable flanking left (5'-end) and right ( 3 '-end) domains, and three conserved sequence blocks (CSBs) in the right domain (Walberg and Clayton 1981; Brown et al. 1986; Saccone et al. 1991). In order to identify these domains and CSBs, determined control region sequences of the Japanese serow were compared with cow (Bos taurus) sequences from Saccone et al. (1991).

The complete control region sequences of the Japanese serow were also compared with sequences from four Caprinae species, i.e. the Formosan serow (Capricornis swinhoei), bezoar (Capra aegagrus), goat (C. hircus), and sheep (Ovis aries). The Formosan serow sequence used in the present study was reported in Horng et al. (2003), which adopted Naemorhedus as the genus for serows. The bezoar and goat sequences were reported in Takada et al. (1997), and the sheep sequence was in Zardoya et al. (1995). These sequences used here have 


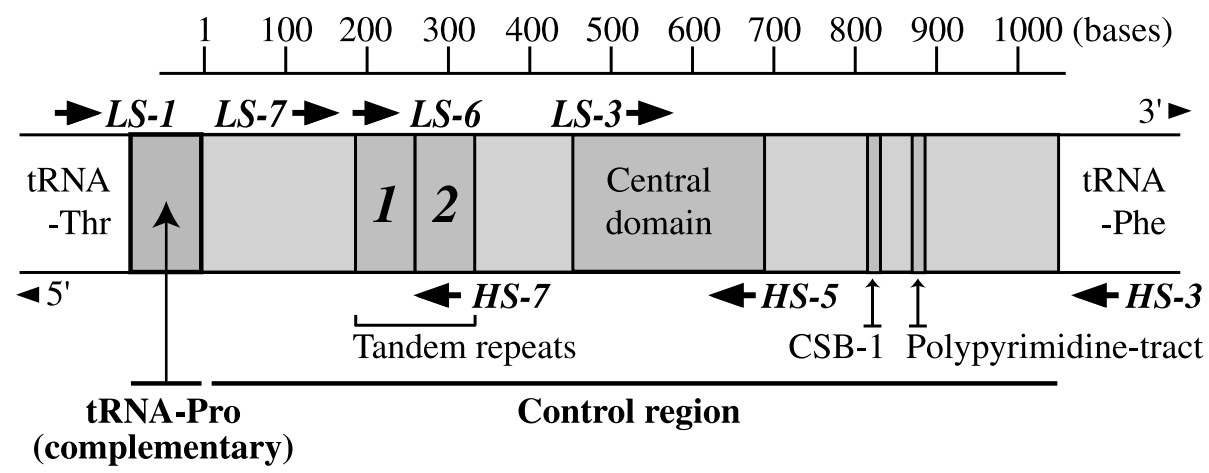

Fig. 2. Diagram of the mtDNA control region ( $1031 \mathrm{bp})$ and the proline tRNA gene ( $65 \mathrm{bp})$ of the Japanese serow. Arrows show the positions of primers used for amplification and/or sequencing. Numbers 1-2 indicate tandem repeat (TR) units (76 bp each).

been deposited in the DDBJ/EMBL/GenBank nucleotide sequence databases with accession numbers AF547433, AB004076, AB004077, and L29055 respectively.

For alignment and analysis of control region sequences the computer software GENETYX-MAC Version 12 (GENETYX Corporation, Japan) and MEGA version 2.1 (Kumar et al. 2001) were used.

\section{Results and discussion}

Nucleotide sequences of the Japanese serow control region

With the primer pair LS-1/HS-3, double-stranded DNAs of about 1100 bp containing the mtDNA control region and its flanking proline tRNA gene were successfully PCR amplified from six serow samples. Using PCR product direct sequencing with seven primers, complete nucleotide sequences of the control region (1031 bp) and the proline tRNA gene (65 bp) were determined. The Japanese serow control region sequence is $60 \%$ A+T-rich, and its size is larger than the $910 \mathrm{bp}$ cow equivalent, whereas considerably smaller than those in Caprinae species, e.g. 1124 bp in the Formosan serow, $1213 \mathrm{bp}$ in bezoar, $1212 \mathrm{bp}$ in goat, and $1189 \mathrm{bp}$ in sheep. The differences in base length are mainly due to length variations at the left domain.

In total, ten variable sites were observed in control region sequences from six samples, resulting in four control region haplotypes, i.e. Kiso-a, Kiso-b, Kiso-c, and Kiso-d (Table 1, Fig. 3), whereas all of the proline tRNA gene sequences were identical. All of the substitutions among these haplotypes are transitions $(\mathrm{A} \leftrightarrow \mathrm{G}$ or $\mathrm{C} \leftrightarrow \mathrm{T})$.

The newly determined nucleotide sequences reported here have been deposited in the DDBJ/EMBL/GenBank nucleotide sequence databases with the accession num-

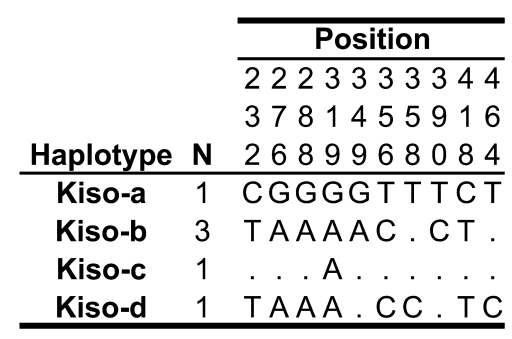

Fig. 3. Ten variable sites in four control region haplotypes from six Japanese serows. Only the sites where substitutions were found among haplotypes are shown. Dots denote identity with nucleotides of Kiso-a.

bers AB055687 (Kiso-a), AB055688 (Kiso-b), AB055689 (Kiso-c), and AB125256 (Kiso-d).

\section{Identification of central domain}

$239 \mathrm{bp}$ (nucleotide positions 459-697) of the Japanese serow control region was identified as the central domain by comparison with cow sequence. Only one variable site among four haplotypes was found at nucleotide position 464 in this central domain (Fig. 3). In the present study, central domains were also identified in the control region sequences of the Formosan serow, bezoar and goat. An alignment of central domains of cow and five Caprinae species is shown in Fig. 4. The central domain sequences of the Japanese serow show similarities of 91\% with cow, and higher similarities (92-96\%) with the other four Caprinae species (Table 3 ).

\section{Right domain and CSBS}

In the right domain, three conserved sequence blocks (CSBs) have been identified in most vertebrates (Walberg and Clayton 1981). The CSB-1 motif has been found commonly in mammals, whereas the CSB-2 and CSB-3 motifs have been controversial in artiodactyls and cetaceans. Saccone et al. (1991) wrote that CSB-2 was 


\begin{tabular}{|c|c|c|c|}
\hline Jap. Serow & 459 & CTTGA & 518 \\
\hline Cow & 368 & 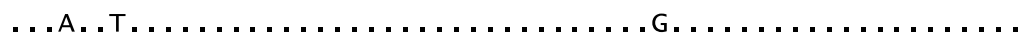 & 427 \\
\hline For. Serow & 534 & 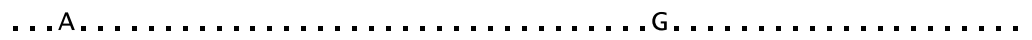 & 593 \\
\hline Bezoar & 648 & 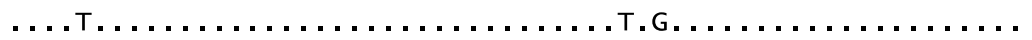 & 707 \\
\hline Goat & 648 & 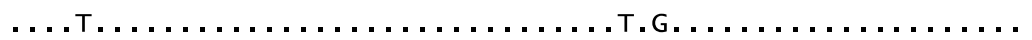 & 707 \\
\hline Sheep & 625 & 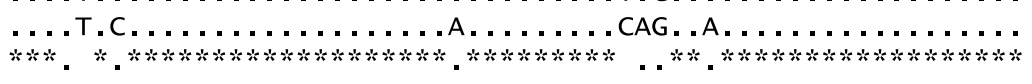 & 684 \\
\hline Jap. Serow & 519 & CGGGCCCATCAATTGTGGGGGTAGCTATTTAATGAACCTTATCAGACATCTGGTTCTTTC & 578 \\
\hline Cow & 428 & $\ldots$. А. СС $\ldots$. & 487 \\
\hline For. Serow & 594 & 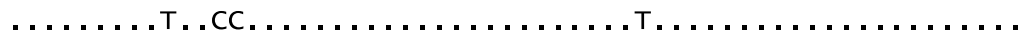 & 653 \\
\hline Bezoar & 708 & 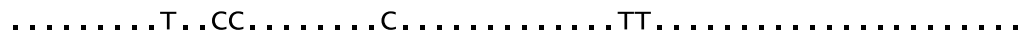 & 767 \\
\hline Goat & 708 & 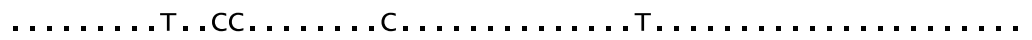 & 767 \\
\hline Sheep & 685 & 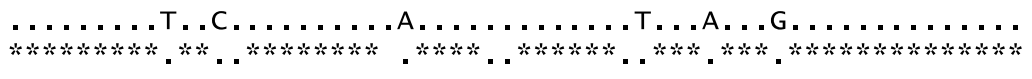 & 744 \\
\hline Jap. & 579 & TTCAGGGCCATCTCACCTAAAATCGCCCACACTTTCCTCTTAAATAAGACATCTCGATGG & 638 \\
\hline Cow & 488 & $\ldots \ldots \ldots \ldots \ldots$ T. $\ldots \ldots$ CG.T. .TT. $\ldots \ldots \ldots \ldots \ldots \ldots \ldots \ldots \ldots$ & 547 \\
\hline For. Serow & 654 & $\ldots \ldots \ldots+\ldots \ldots \ldots \ldots \ldots$ & 713 \\
\hline Bezoar & 768 & 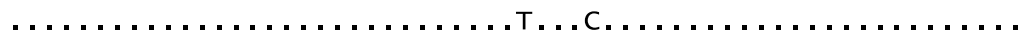 & 827 \\
\hline Goat & 768 & $\ldots \ldots \ldots \ldots \ldots \ldots \ldots$ т.. с... & 827 \\
\hline Sheep & 745 & 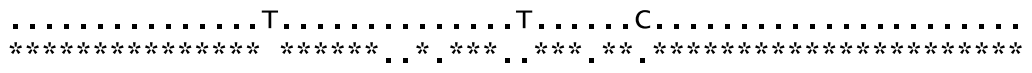 & 804 \\
\hline Jap. Serow & 639 & ACTAATGACTAATCAGCCCATGCCCACACATAACTGTGCTGTCATGCATTTGGTATTTT & 697 \\
\hline Cow & 548 & 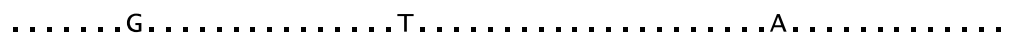 & 606 \\
\hline For. Serow & 714 & 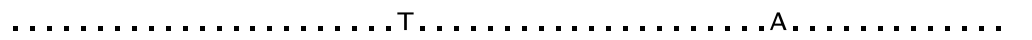 & 672 \\
\hline Bezoar & 828 & 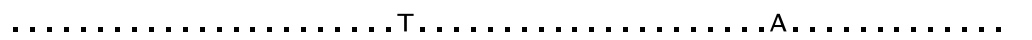 & 886 \\
\hline Goat & 828 & $\ldots \ldots$...... & 886 \\
\hline Sheep & 805 & NG & 862 \\
\hline
\end{tabular}

Fig. 4. Alignment of central domain sequences of mtDNA control region in six species. Haplotype Kiso-a was used as the representative sequence of the Japanese serow. Only sites where substitutions were found are shown. Dots denote identity with nucleotides of Japanese serow. Dashes denote spaces for alignment.

Table 3. Sequence similarities for central domain and CSB-1 between Japanese serow* and five other species.

\begin{tabular}{lcc}
\hline & \multicolumn{2}{c}{ Similarity (\%) } \\
\cline { 2 - 3 } & $\begin{array}{c}\text { Central domain } \\
(238-239 \mathrm{bp})\end{array}$ & $\begin{array}{c}\text { CSB-1 } \\
(26 \mathrm{bp})\end{array}$ \\
\hline Cow & 91 & 92 \\
For. Serow & 96 & 85 \\
Bezoar & 95 & 88 \\
Goat & 95 & 88 \\
Sheep & 92 & 92 \\
\hline
\end{tabular}

*Haplotype Kiso-a was used as a representative sequence of the Japanese serow.

restricted to a run of only five $\mathrm{Cs}$ in cow, and CSB-3 was completely absent in cow and dolphin. Zardoya et al. (1995) found a polypyrimidine tract localized between CSB-1 and the phenylalanine tRNA gene in sheep, and suggested that the polypyrimidine tract might be a common property of artiodactyl species. On the other hand, Ghivizzani et al. (1993) suggested that CSB-2 and CSB-3 elements in most vertebrates became a hybrid sequence which contained two spaced runs of $\mathrm{C}$ residue in the cow, and in all artiodactyls except Suidae. They labeled this sequence "CSB-2 +3 ".

In the right domain (nucleotide positions 698-1031) of the Japanese serow, a motif of 26 bp (nucleotide positions 814-839) was identified as the CSB-1 by comparison with cow sequences. Also, a polypyrimidine tract sequence containing runs of $\mathrm{C}$ residue was found at nucleotide positions 874-893 downstream of CSB-1. Homologous sequences of CSB-1 and a polypyrimidine tract were also identified in the four other Caprinae species. The part of the mtDNA control region alignments containing the CSB- 1 and CSB- 2 motifs (or polypyrimidine tract) is shown in Fig. 5. CSB-1 motifs were well-conserved among these six species. Sequence similarities of CSB-1 motifs among them are shown in Table 3. The polypyrimidine tract regions seem to be well-conserved among the five Caprinae species, and are similar to some extent to CSB-2 in dolphin shown in Saccone et al. (1991). But the cow "CSB-2 + 3" region indicated by Ghivizzani et al. (1993) does not seem to show as high similarity to the five Caprinae species as it showed to giraffe and water buffalo in the article. 


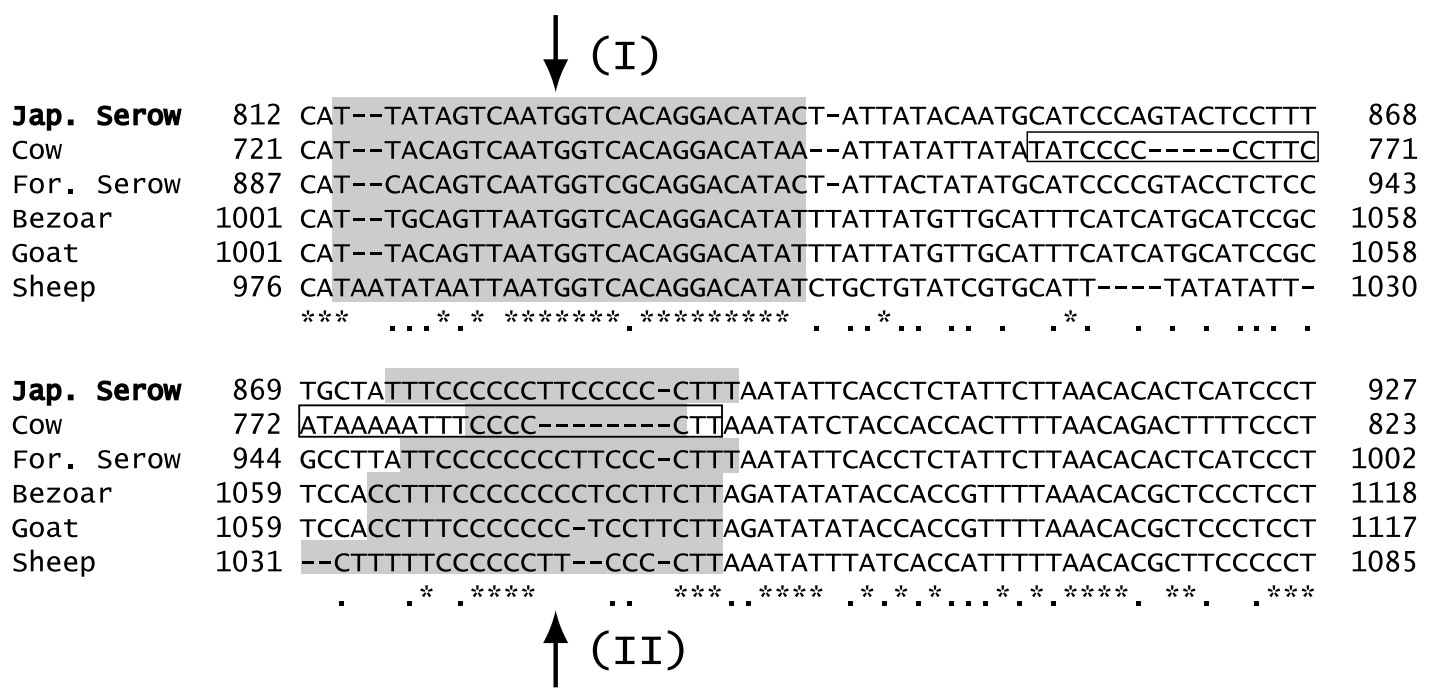

Fig. 5. Part of the mtDNA control region alignment in six species, containing CSB-1 and CSB-2 motifs (or polypyrimidine tract). Shadowed sequences (I) are CSB-1 motifs in six species. Shadowed sequences (II) are CSB-2 motif from the cow, identified in Saccone et al. (1991), and polypyrimidine tracts in sheep and in other four Caprinae species, identified in Zardoya et al. (1995) and in the present study, respectively. An open box in the cow sequence indicates the "CSB-2 + 3" region in Ghivizzani et al. (1993). Dashes denote spaces for alignment.

\section{Left domain and tandem repeats}

The left domain is characterized by high substitution rates in most mammalian species. In the Japanese serow, nine of ten variable sites among four control region haplotypes were found in the left domain (nucleotide positions 1-458) (Fig. 3). The proportion of variable sites was $2.0 \%$ in 458 bp of the left domain, whereas only one $(0.4 \%)$ variable site was observed in $239 \mathrm{bp}$ of the central domain, and none in $334 \mathrm{bp}$ of the right domain.

There have been a number of reports of tandemly repeated sequences in mammalian control regions (reviewed in Fumagalli et al. 1996). Tandem repeats in the left domain have been reported in sheep (Zardoya et al. 1995; Wood and Phua 1996), sika deer (Douzery and Randi 1997; Nagata et al. 1998; Cook et al. 1999), and evening bat (Wilkinson and Chapman 1991), whereas in some other species tandem repeats have been found in the right domain (e.g. green monkey in Karawya and Martin 1987; rabbit in Mignotte et al. 1990; platypus in Gemmell et al. 1996).

In the present study, two tandemly repeated sequences of $76 \mathrm{bp}$ were found at nucleotide positions 194-269 and 270-345 in the left domain of the Japanese serow (Fig. 2). The arrangement and motif of the repeat sequences are similar to four tandem repeats of $75 \mathrm{bp}$ reported in sheep (Zardoya et al. 1995; Wood and Phua 1996). In these articles, the repeat units were described differently in length and position, but in fact these repeats are identical. Sequences that are homologous to the tandem repeats of the Japanese serow were also identified in the control region sequences of the Formosan serow, bezoar and goat. Three and two tandem repeats were recognized in the Formosan serow and two Capra species respectively. These homologous tandem repeat (TR) units from the Caprinae species are shown in Fig. 6 , and the sequence similarities among them are shown in Table 4. Sequence similarities between two tandem repeat units in the Japanese serow (Kiso-a) were comparatively low (80\%), whereas extremely high (97-99\%) among four units in sheep. These results indicate that the divergence time of the tandem repeat in the Japanese serow is probably much longer than that in sheep. The first tandem repeat unit (TR-1) of the Formosan serow showed rather low sequence similarities (71-79\%) not only with two other units of the Formosan serow but also with all units of the other species. This probably means that the TR-1 of the Formosan serow occurred long before another repeat unit (TR-2 or TR-3) was generated. On the other hand, sequence similarities between the same units of bezoar and goat were extremely high (99\%), as was the whole control region sequence similarity ( $99 \%$ in 1212 bp) between these two species. This indicates that bezoar and goat must be extremely closely related species, as Takada et al. (1997) showed.

All of these repeat units contain two short sections of mirror symmetry (TACAT, ATGTA) (Fig. 6). In the Japanese serow, they are located at nucleotide positions 194-212 and 225-239 in the first repeat unit (TR-1), and 


\begin{tabular}{|c|c|c|c|}
\hline Jap. Serow & $\begin{array}{l}\text { TR-1 } \\
\text { TR-2 }\end{array}$ & $\begin{array}{l}194 \\
270\end{array}$ & 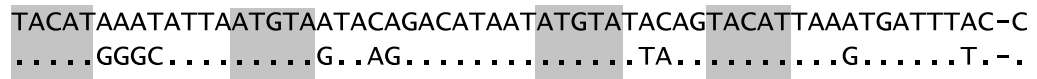 \\
\hline For. Serow & $\begin{array}{l}\text { TR-1 } \\
\text { TR-2 } \\
\text { TR-3 }\end{array}$ & $\begin{array}{l}193 \\
269 \\
345\end{array}$ & 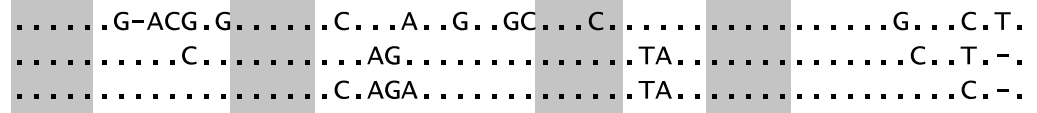 \\
\hline Bezoar & $\begin{array}{l}\text { TR-1 } \\
\text { TR-2 }\end{array}$ & $\begin{array}{l}385 \\
461\end{array}$ & 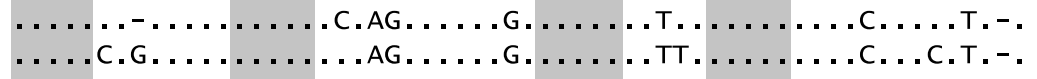 \\
\hline Goat & $\begin{array}{l}\text { TR-1 } \\
\text { TR-2 }\end{array}$ & $\begin{array}{l}385 \\
461\end{array}$ & 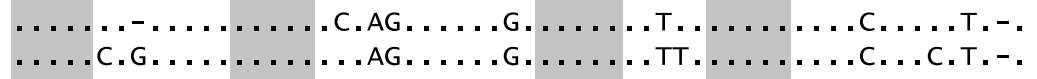 \\
\hline Sheep & $\begin{array}{l}\text { TR-1 } \\
\text { TR-2 } \\
\text { TR-3 } \\
\text { TR-4 }\end{array}$ & $\begin{array}{l}215 \\
290 \\
365 \\
440\end{array}$ & 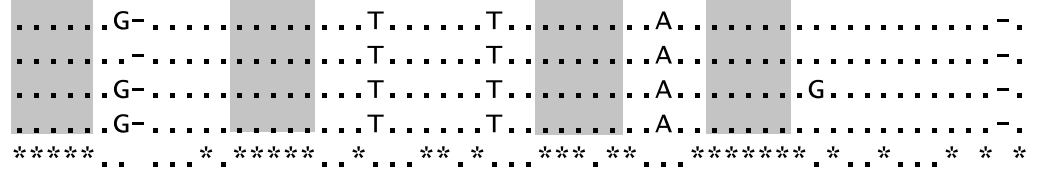 \\
\hline Jap. Serow & $\begin{array}{l}\text { TR-1 } \\
\text { TR-2 }\end{array}$ & $\begin{array}{l}253 \\
329\end{array}$ & $\begin{array}{l}\text { CCATGCGTAT-AAGCATG } \\
\text {.T.C...........A. }\end{array}$ \\
\hline For. Serow & $\begin{array}{l}\mathrm{TR}-1 \\
\mathrm{TR}-2 \\
\mathrm{TR}-3\end{array}$ & $\begin{array}{l}252 \\
328 \\
404\end{array}$ & 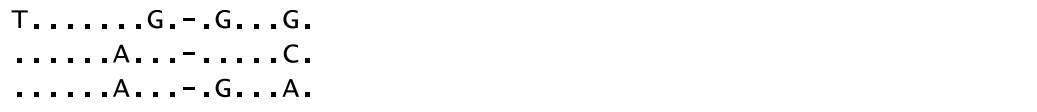 \\
\hline Bezoar & $\begin{array}{l}\text { TR-1 } \\
\text { TR-2 }\end{array}$ & $\begin{array}{l}443 \\
520\end{array}$ & 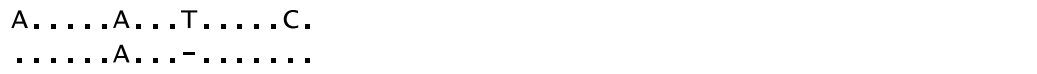 \\
\hline Goat & $\begin{array}{l}\text { TR-1 } \\
\text { TR-2 }\end{array}$ & $\begin{array}{l}443 \\
520\end{array}$ & $\begin{array}{l}\text { А. . . A. .T. .G.C. } \\
\text { T...A...... }\end{array}$ \\
\hline Sheep & $\begin{array}{l}\text { TR-1 } \\
\text { TR-2 } \\
\text { TR-3 } \\
\text { TR-4 }\end{array}$ & $\begin{array}{l}273 \\
348 \\
423 \\
498\end{array}$ & 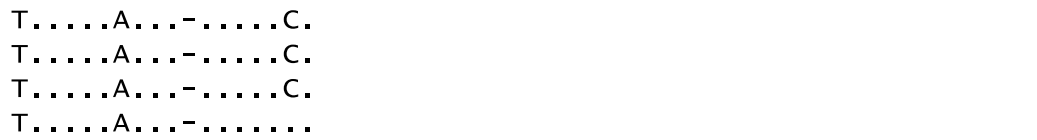 \\
\hline
\end{tabular}

Fig. 6. Alignment of tandem repeat (TR) units of five Caprinae species. Haplotype Kiso-a was used as a representative sequence of the Japanese serow. Shadowed sequences are mirror symmetry sequences (TACAT, ATGTA). Only the sites where substitutions were found are shown. Dots denote identity with nucleotides in the first unit (TR-1) of the Japanese serow. Dashes denote spaces for alignment.

Table 4. Sequence similarities (\%) among tandem repeat units of five Caprinae species.

\begin{tabular}{|c|c|c|c|c|c|c|c|c|c|c|c|c|c|c|}
\hline & & \multicolumn{2}{|c|}{ Jap. Serow* } & \multicolumn{3}{|c|}{ For. Serow } & \multicolumn{2}{|c|}{ Bezoar } & \multicolumn{2}{|c|}{ Goat } & \multicolumn{4}{|c|}{ Sheep } \\
\hline & & TR-1 & TR-2 & TR-1 & TR-2 & TR-3 & TR-1 & TR-2 & TR-1 & TR-2 & TR-1 & TR-2 & TR-3 & TR-4 \\
\hline \multirow[t]{2}{*}{ Jap. Serow* } & TR-1 & & & & & & & & & & & & & \\
\hline & TR-2 & 80 & & & & & & & & & & & & \\
\hline \multirow[t]{3}{*}{ For. Serow } & TR-1 & 79 & 76 & & & & & & & & & & & \\
\hline & TR-2 & 88 & 86 & 71 & & & & & & & & & & \\
\hline & TR-3 & 87 & 84 & 77 & 91 & & & & & & & & & \\
\hline \multirow[t]{2}{*}{ Bezoar } & TR-1 & 87 & 81 & 73 & 89 & 88 & & & & & & & & \\
\hline & TR-2 & 86 & 82 & 71 & 86 & 83 & 92 & & & & & & & \\
\hline \multirow[t]{2}{*}{ Goat } & TR-1 & 85 & 80 & 73 & 88 & 87 & 99 & 91 & & & & & & \\
\hline & TR-2 & 84 & 80 & 72 & 84 & 82 & 92 & 99 & 91 & & & & & \\
\hline \multirow[t]{4}{*}{ Sheep } & TR-1 & 91 & 83 & 76 & 88 & 85 & 87 & 83 & 85 & 84 & & & & \\
\hline & TR-2 & 92 & 81 & 74 & 89 & 87 & 88 & 84 & 87 & 85 & 99 & & & \\
\hline & TR-3 & 89 & 81 & 74 & 87 & 84 & 85 & 81 & 84 & 83 & 99 & 97 & & \\
\hline & TR-4 & 92 & 83 & 76 & 87 & 85 & 85 & 84 & 84 & 85 & 99 & 97 & 97 & \\
\hline
\end{tabular}

*Haplotype Kiso-a was used as a representative sequence of the Japanese serow. 
at corresponding positions in the second unit (TR-2). Although the left domain is characterized by high substitution rates, and sequence similarities varied among these tandem repeat units as stated above, these short sections were extremely conserved among these five Caprinae species, and also among the four haplotypes of the Japanese serow. No substitution was found in these mirror symmetry sequences (TACAT, ATGTA) except for only one substitution in TR-1 of the Formosan serow (Fig. 3, Fig. 6). These short sections were thought to be able to form very stable hairpin loops which might be involved as a recognition site for the arrest of H-strand synthesis (Saccone et al. 1991). Results in the present study indicate the functional importance of these short sections of mirror symmetry sequences.

In sika deer, tandem repeat units of $37-40 \mathrm{bp}$ at similar positions in the left domain were recognized, and the copy number of repeat units varied from three to seven among local populations (Nagata et al. 1998, 1999; Cook et al. 1999). This variation caused intraspecific size polymorphism of the control region in sika deer. In the present study, no variation of the copy number of $76 \mathrm{bp}$ repeat units was observed in the six Japanese serow samples. Further investigation based on more samples from various localities is necessary to clarify the intraspecific variation in the Japanese serow.

\section{The genetic distances between the Japanese serow and the Formosan serow}

The genetic distances of the complete control region among the Japanese serow haplotypes and the Formosan serow were estimated by Kimura's two-parameter method. The estimated distances between the Japanese serow haplotypes and the Formosan serow ranged 11.95$12.31 \%$, whereas the distances among four Japanese serow haplotypes ranged $0.10-0.78 \%$. Loftus et al. (1994) estimated the substitution rate between bison and cattle at $10.62 \%$ per 1 million year (Myr), using more variable short sequence ( $375 \mathrm{bp}$ ) of the control region. Since the complete control region contains more conserved sequences, the substitution rate of the complete control region will probably be lower than the rate estimated by Loftus et al. (1994). The estimated genetic distances indicate that the divergence time between the Japanese serow and the Formosan serow is probably much longer than 1 Myr. Further discussion on the relationship among three Capricornis species may not be possible because no sequence data for the serow $(C$. sumatraensis) control region is available. At least, the estimated genetic distances and the existence of three tandem repeat units suggest that the Formosan serow is probably a distinct species from the Japanese serow. Since species definition should not rely solely on molecular data, reexamination of the taxonomy of Capricornis species should be carried out by further morphological and ecological studies.

Acknowledgments: The author is grateful to officials of Kiso-fukushima Town and Dr. Hisashi Matsubayashi for the kind assistance in collecting tissue samples from culled serows. The author especially thanks Dr. Hidetoshi Tamate for his kind encouragement and useful comments on the manuscript. Thanks are also due to two anonymous reviewers and Dr. Richard P. Shefferson for improving the manuscript.

\section{References}

Anderson, S., Bankier, A. T., Barrell, B. G., de Bruijn, M. H. L., Coulson, A. R., Drouin, J., Eperon, I. C., Nierlich, D. P., Roe, B. A., Sanger, F., Schreier, P. H., Smith, A. J. H., Staden, R. and Young, I. G. 1981. Sequence and organization of the human mitochondrial genome. Nature 290: 457-465.

Anderson, S., de Bruijn, M. H. L., Coulson, A. R., Eperon, I. C., Sanger, F. and Young, I. G. 1982. Complete sequence of bovine mitochondrial DNA - conserved features of the mammalian mitochondrial genome. Journal of Molecular Biology 156: 683717.

Arctander, P., Kat, P. W., Aman, R. A. and Siegismund, H. R. 1996. Extreme genetic differences among populations of Gazella granti, Grant's gazelle, in Kenya. Heredity 76: 465-475.

Birungi, J. and Arctander, P. 2000. Large sequence divergence of mitochondrial DNA genotypes of the control region within populations of the African antelope, kob (Kobus kob). Molecular Ecology 9: 1997-2008.

Brown, G. G., Gedaleta, G., Pepe, G., Saccone, C. and Sbisà, E. 1986. Structural conservation and variation in the D-loop-containing region of vertebrate mitochondrial DNA. Journal of Molecular Biology 192: 503-511.

Brown, W. M., George, M. Jr. and Wilson, A. C. 1979. Rapid evolution of animal mitochondrial DNA. Proceedings of the National Academy of Sciences of the United States of America 76: 1967-1971.

Chikuni, K., Mori, Y., Tabata, T., Saito, M., Monma, M. and Kosugiyama, M. 1995. Molecular phylogeny based on the $\kappa$ casein and cytochrome $b$ sequences in the mammalian suborder Ruminantia. Journal of Molecular Evolution 41: 859-866.

Cook, C. E., Wang, Y. and Sansabaugh, G. 1999. A mitochondrial control region and cytochrome $b$ phylogeny of sika deer (Cervus nippon) and report of tandem repeats in the control region. Molecular Phylogeny and Evolution 12: 47-56.

Corbet, G. B. 1978. The Mammals of the Palaearctic Region: A Taxonomic Review. Cornell University Press, London and Ithaca, 314 pp.

Corbet, G. B. and Hill, J. E. 1992. The Mammals of the Indomalayan Region: A Systematic Review. Oxford University Press, Oxford, 488 pp. 
Dolan, J. M. 1963. Beitrag zur systematischen Gliederung des Tribus Rupicaprini Simpson, 1945. Zeitschrift für zoologische Systematik und Evolutionsforschung 1: 311-407.

Douzery, E. and Randi, E. 1997. The mitochondrial control region of Cervidae: evolutionary patterns and phylogenic content. Molecular Biology and Evolution 14: 1154-1166.

Fumagalli, L., Taberlet, P., Favre, L. and Hausser, J. 1996. Origin and evolution of homologous repeated sequences in the mitochondrial DNA control region of shrews. Molecular Biology and Evolution 13: 31-46.

Gemmell, N. J., Western, P. S., Watson, J. M. and Marshall Graves, J. A. 1996. Evolution of the mammalian mitochondrial control region - comparisons of control region sequences between monotreme and therian mammals. Molecular Biology and Evolution 13: 798-808.

Ghivizzani, S. C., Mackay, S. L. D., Madsen, C. S., Laipis, P. J. and Hauswirth, W. W. 1993. Transcribed heteroplasmic repeated sequences in the porcine mitochondrial DNA D-loop region. Journal of Molecular Evolution 37: 36-47.

Giles, R. E., Blanc, H., Cann, H. M. and Wallace, D. C. 1980. Maternal inheritance of human mitochondrial DNA. Proceedings of the National Academy of Sciences of the United States of America 77: 6715-6719.

Groves, C. P. and Grubb, P. 1985. Reclassification of the serows and gorals (Nemorhaedus: Bovidae). In (S. Lovari, ed.) The Biology and Management of Mountain Ungulates. Pp. 45-50. Croon Helm, London.

Grubb, P. 1993. Order Artiodactyla. In (D. E. Wilson and D. M. Reeder, eds.) Mammal Species of the World: A Taxonomic and Geographic Reference, 2nd ed. Pp. 377-414. Smithsonian Institution Press, Washington and London.

Horng, D.-C., Huang, H.-W., Liang, Y.-C. and Ou, B.-R. 2003. Two distinct phylogenetic groups of Formosan serow (Naemorhedus swinhoei Gray) population in Taiwan: based on mitochondrial D-loop region sequences. Tèyou Shengwù Yánjiu [Endemic Species Research] 5: 15-25 (in Chinese with English abstract).

Karawya, E. M. and Martin, R. G. 1987. Monkey (CV-1) mitochondrial DNA contains a unique triplication of $108 \mathrm{bp}$ in the origin region. Biochimica et Biophysica Acta 909: 30-34.

Kocher, T. D., Thomas, W. K., Meyer, A., Edwards, S. V., Pääbo, S., Villablanca, F. X. and Wilson, A. C. 1989. Dynamics of mitochondrial DNA evolution in animals: amplification and sequencing with conserved primers. Proceedings of the National Academy of Sciences of the United States of America 86: 6196-6200.

Kumar, S., Tamura, K., Jakobsen, I. B. and Nei, M. 2001. MEGA2: Molecular evolutionary genetics analysis software. Bioinformatics 17: $1244-1245$.

Loftus, R. T., MacHugh, D. E., Bradley, D. G., Sharp, P. M. and Cunningham, P. 1994. Evidence for two independent domestications of cattle. Proceedings of the National Academy of Sciences of the United States of America 91: 2757-2761.

Marmi, J., Bertranpetit, J., Terradas, J., Takenaka, O. and DomingoRoura, X. 2004. Radiation and phylogeography in the Japanese macaque, Macaca fuscata. Molecular Phylogeny and Evolution 30: 676-685.

Maruyama, N., Ikeda, H., Hanai, M. and Tokida, K. 1997. Japan. In (D. M. Shackleton, ed.) Wild Sheep and Goats and their Relatives. Pp. 271-274. IUCN, Gland and Cambridge.

Matsuhashi, T., Masuda, R., Mano, T. and Yoshida, M. C. 1999. Microevolution of the mitochondrial DNA control region in the Japanese brown bear (Ursus arctos) population. Molecular Biology and Evolution 16: 676-684.

Matthee, C. A. and Robinson, T. J. 1999. Mitochondrial DNA popu- lation structure of roan and sable antelope: implications for the translocation and conservation of the species. Molecular Ecology 8: $227-238$.

Mead, J. I. 1989. Nemorhaedus goral. Mammalian Species 335: 1-5.

Mignotte, F., Gueride, M., Champagne, A.-M. and Mounolou, J.-C. 1990. Direct repeats in the non-coding region of rabbit mitochondrial DNA. European Journal of Biochemistry 194: 561-571.

Min, M.-S., Okumura, H., Jo, D.-J., An, J.-H., Kim, K.-S., Kim, C.-B., Shin, N.-S., Lee, M.-H., Han, C.-H., Voloshina, I. V. and Lee, H. 2004. Molecular phylogenetic status of the Korean goral and Japanese serow based on partial sequences of the mitochondrial cytochrome $b$ gene. Molecules and Cells 17: 365-372.

Nagata, J., Masuda, R., Kaji, K., Kaneko, M. and Yoshida, M. C. 1998. Genetic variation and population structure of the Japanese sika deer (Cervus nippon) in Hokkaido Island, based on mitochondrial D-loop sequences. Molecular Ecology 7: 871-877.

Nagata, J., Masuda, R., Tamate, H. B., Hamasaki, S., Ochiai, K., Asada, M., Tatsuzawa, S., Suda, K., Tado, H. and Yoshida, M. C. 1999. Two genetically distinct lineages of the sika deer, Cervus nippon, in Japanese islands: comparison of mitochondrial D-loop region sequences. Molecular Phylogeny and Evolution 13: 511519.

Nowak, R. M. 1999. Walker's Mammals of the World, 6th ed. The Johns Hopkins University Press, Baltimore and London, 1936 pp.

Saccone, C., Pesole, G. and Sbisá, E. 1991. The main regulatory region of mammalian mitochondrial DNA: structure-function model and evolutionary pattern. Journal of Molecular Evolution 33: 83-91.

Simpson, G. G. 1945. The Principles of classification and a classification of mammals. Bulletin of the American Museum of Natural History 85: 1-350.

Takada, T., Kikkawa, Y., Yonekawa, H., Kawakami, S. and Amano, T. 1997. Bezoar (Capra aegagrus) is a matriarchal candidate for ancestor of domestic goat (Capra hircus): evidence from the mitochondrial DNA diversity. Biochemical Genetics 35: 315 326.

Walberg, M. W. and Clayton, D. A. 1981. Sequence and properties of the human KB cell and mouse L cell D-loop regions of mitochondrial DNA. Nucleic Acids Research 9: 5411-5421.

Watanobe, T., Ishiguro, N. and Nakano, M. 2003. Phylogeography and population structure of the Japanese wild boar Sus scrofa leucomystax: mitochondrial DNA variation. Zoological Science 20: 1477-1489.

Wilkinson, G. S. and Chapman, A. M. 1991. Length and sequence variation in evening bat D-loop mtDNA. Genetics 128: 607-617.

Wilson, A. C., Cann, R. L., Carr, S. M., George, M., Gyllensten, U. B., Helm-Bychowski, K. M., Higuchi, R. G., Palumbi, S. R., Prager, E. M., Sage, R. D. and Stoneking, M. 1985. Mitochondrial DNA and two perspectives on evolutionary genetics. Biological Journal of the Linnean Society 26: 375-400.

Wood, N. J. and Phua, S. H. 1996. Variation in the control region sequence of the sheep mitochondrial genome. Animal Genetics 27: 25-33.

Yoshida, H., Yoshioka, M., Shirakihara, M. and Chow, S. 2001. Population structure of finless porpoises (Neophocaena phocaenoides) in coastal waters of Japan based on mitochondrial DNA sequences. Journal of Mammalogy 82: 123-130.

Zardoya, R., Villalta, M., López-Pérez, M. J., Garrido-Pertierra, A., Montoya, J. and Bautista, J. M. 1995. Nucleotide sequence of the sheep mitochondrial DNA D-loop and its flanking tRNA genes. Current Genetics 28: 94-96. 